\title{
The effect of smoking on the development of allergic disease and specific immunological responses in a factory workforce exposed to humidifier contaminants
}

\author{
M J Finnegan, Sally Little, D J Gordon, P K C Austwick, Rosemary D Tee, A J Nunn, \\ A J Newman-Taylor
}

\begin{abstract}
The effects of smoking on the development of work related asthma and on the production of specific IgE and IgG antibodies to antigen from a contaminated humidifier are described for a sample of 258 workers from a printing factory. Current smoking was associated with low production of IgG antibody but with higher production of IgE antibody. No dose response for either antibody was found when numbers of cigarettes or pack-years smoked were considered. Work related asthma was detected in 12 workers by peak flow recordings. Six were current smokers and one was an ex-smoker. One subject with work related asthma had a high (and one a marginal) concentration of specific IgE to humidifier antigen.
\end{abstract}

Tobacco smoking has been found to influence specific immunological responses to agents inhaled at work. Current smokers exposed both to inhaled proteins $^{1-3}$ and low molecular weight hapten ${ }^{4}$ are more likely than non-smokers to develop specific IgE antibodies and asthma. ${ }^{124}$ Paradoxically, current smokers who inhale organic dusts such as mouldy hay and avian proteins, which cause allergic alveolitis, are less likely to develop precipitating and

Brompton Hospital, Fulham Road, London SW3 6HP

M J Finnegan

Robens Institute of Industrial and Environmental Health and Safety, University of Surrey, Guildford, Surrey GU2 5XH

Sally Little, P K C Austwick

Department of Occupational Medicine, National Heart and Lung Institute, Dovehouse Street, London SW3

D J Gordon, Rosemary D Tee, A J Newman-Taylor

Department of Epidemiology, National Heart and Lung Institute, Fulham Road, London SW3

A J Nunn specific IgG antibody..$^{56}$ One previous study has examined the effect of tobacco smoking on both specific IgE and IgG antibody responses. This study of a workforce preparing prawns found that the prevalence of specific IgE was greater and that of IgG was less among current smokers than among nonsmokers. ${ }^{3}$

We have examined IgE and IgG responses to airborne antigen in a factory population exposed to contaminated humidifiers (the results of precipitin tests have already been reported for this population). ${ }^{5}$ We have examined the relation of these responses to smoking habits and the $\operatorname{IgE}$ response to the development of work related asthma.

\section{Subjects and methods}

The study population was the workforce of a printing factory that was supplied with humidified air by two large water spray humidifiers. At the time of the study these had been operational for 19 years. Both the sump tanks and the eliminator plates were heavily contaminated by a dark brown jelly-like slime. The workforce was investigated to determine the cause of an outbreak of asthma. During the investigation the employees answered a modified Medical Research Council questionnaire administered by an interviewer. This included questions about occupational history, history of smoking, and the relation of respiratory symptoms (wheezing, shortness of breath, and chest tightness) to periods at work. Serum samples were obtained from all who consented.

Subjects were categorised on the basis of answers to the questionnaire into current smokers if they smoked one or more cigarettes a day, never smokers if they had never smoked or smoked less than one cigarette a day, and ex-smokers if they had stopped smoking for at least six months. Ex-smokers were included with never smokers in a group called nonsmokers. Ex-smokers were asked the year in which they stopped smoking. Current and ex-smokers were 
asked to estimate the average number of cigarettes smoked a day. The number of pack-years smoked was calculated from this as: pack-years $=$ average daily consumption $\times$ number of years of smoking/ 20.

Jelly scraped from the eliminator plates at the time of the investigation was freeze dried. This was designated humidifier associated antigen (HAA). Subsequently an extract of HAA was prepared at a concentration of $30 \mathrm{mg} / \mathrm{ml}$ in normal saline for serological testing and at a concentration of $10 \mathrm{mg} / \mathrm{ml}$ in Cocas' glycerol solution for skin prick testing.

Skin prick tests were made on volunteers with Cocas' glycerol (as control solution) and extracts of cat fur, mixed grass pollen and $D$ pteronyssinus (Bencard), and HAA in Cocas' glycerol. A positive skin test response was defined as a weal with a diameter at least $2 \mathrm{~mm}$ greater than the response to the control solution after 20 minutes. Subjects with one or more positive skin tests to the nonoccupational antigens were considered atopic.

Subjects with work related respiratory symptoms, identified by questionnaire, were asked to make serial recordings of peak expiratory flow rate (PEFR) at two hourly intervals from waking to sleeping during a period of two weeks. The maximum, minimum, and mean PEFR for each 24 hour period were plotted, distinction being made between days at work and days at home. Four readings a day were taken as a minimum but in most cases at least seven readings were recorded. Diurnal variation was calculated by subtracting the minimum from the maximum PEFR on each day and expressing this as a percentage of the maximum PEFR on that day. Asthma was diagnosed if the daily diurnal variation (excluding the first two days) was $20 \%$ or more. Work related asthma was diagnosed if there was a definite deterioration at work with recovery during periods away from work in three of every four periods at work. ${ }^{78}$

Precipitating antibodies to HAA were identified by double diffusion in agar gel as previously reported and validated. ${ }^{9}$ Specific IgG to the jelly extract was identified by enzyme linked immunosorbent assay (ELISA). The wells of microhaemagglutination plates were coated with HAA $(200 \mu \mathrm{l}$ per well of a solution $(100 \mu \mathrm{g} / \mathrm{ml})$ in carbonate buffer, $\mathrm{pH} 9 \cdot 6)$ and left overnight at $4^{\circ} \mathrm{C}$. Appropriate concentrations of antigen had been determined by chequerboard titration using a known negative, a weak, and a strong precipitating serum. After three washes in phosphate buffered saline Tween, $200 \mu 1$ of a 1:100 dilution of test serum was added to individual wells and incubated at room temperature for two hours. After three further washes, $200 \mu \mathrm{l}$ of a conjugated antihuman IgG labelled with alkaline phosphatase (Miles Laboratories) was added and the plates incubated for three hours. After three further washes, $200 \mu \mathrm{l}$ of a $1 \mathrm{mg} / \mathrm{ml}$ solution of p-nitrophenyl-phosphate (Sigma 104) was added. The re- action was stopped after $\overline{3} 0$ minutes by addition of $50 \mu \mathrm{l} 3 \mathrm{M}$ sodium hydroxide and the absorbance of each test was determined photometrically at $405 \mathrm{~nm}$. All assays were performed in duplicate and the mean of the two results was used for analysis.

Specific IgE to HAA was identified by a radioallergosorbent test (RAST). Ten milligrams of lyophilised jelly extract were coupled per $\mathbf{g}$ of cyanogen bromide activated Sepharose 4B (Pharmacia). Optimum assay conditions were determined as two 16 hour incubations with $50 \mu \mathrm{l}$ of serum and $100 \mu \mathrm{l}$ of allergen/sepharose complex (five vol\% concentration) in the first and $50 \mu \mathrm{l}$ of iodine ${ }^{125}$ labelled antiIgE (Pharmacia) in the second. Sera from cord blood with no demonstrable $\operatorname{IgE}$ were used in all assays as negative controls. Sera known to have high total IgE concentrations were also used as controls to detect non-specific binding of IgE to antigen. All assays were performed in duplicate and the mean of the two results used.

\section{STATISTICAL ANALYSIS}

For precipitin reactions and specific IgG, the effects of the variables under consideration were determined by stepwise linear regression analysis. This could not be done for specific IgE because the variance of the data was unequal even after log transformation. As the number of cases with positive reactions to specific IgE was small compared with the number with precipitating antibodies and specific IgG, a value for concentration of specific IgE was chosen as a cut off between normal and raised concentrations. This was done in two ways; firstly by selecting the value of $\mathrm{IgE}$ (RAST) that $95 \%$ of the never smokers fell below, and secondly by taking the level of log transformed IgE (RAST) of the never smokers that corresponded to the geometric mean plus 1.64 standard deviations (SD) as the upper limit of normal.

\section{Results}

POPULATION

Of the 258 workers interviewed, 203 gave a blood sample. All of these were tested for precipitating and specific antibodies to HAA. Later, during a move to a different laboratory, some sera were mislaid and only 126 were available for specific IgE measurements. These included 11 of the 12 workers with work related asthma. In the 203 sera a strong negative correlation was found between strength of precipitin reaction to HAA and intensity of current smoking, with never smokers having strongly positive precipitins; the values of ex-smokers were intermediate. ${ }^{5}$

\section{SKIN PRICK TESTS}

One hundred and three subjects volunteered for skin testing. Thirty three of these were atopic; 10 gave positive reactions to HAA and seven of these were atopic. 
WORK RELATED ASTHMA

Twelve subjects were found by peak flow records to have work related asthma. Six of these were current smokers, one was an ex-smoker, and five were never smokers. Specific IgE measurements were made on 11 of these subjects and it was appreciably raised in only one (isotope binding $15 \cdot 4 \%$ ). One other subject had a marginal concentration (see below) of specific IgE RAST ( $0 \cdot 8 \%$ binding).

\section{SEROLOGY: NORMAL IGE CONCENTRATIONS}

Determinations of specific IgE were made in 126 subjects and these formed the group for analysis. Based on the value of IgE RAST above the 95th percentile of the never smokers, a level of $1 \%$ binding (natural $\log$ of $1=0$ ) or more was taken as abnormal. For the geometric mean of the log transformed RAST results of the never smokers plus $1.64 \mathrm{SD}$, $0.71 \%$ binding (natural $\log$ of $0.71=-0.34$ ) or above was taken as abnormal.

\section{SEROLOGY: PRECIPITATING ANTIBODIES TO HAA}

The same strong negative correlation between current smoking and precipitating antibodies was detected amongst these 126 sera as was previously reported. ${ }^{5}$ No correlation was found with atopy or positive skin prick test to HAA and similarly, no correlation existed between specific IgE and precipitin values.

\section{SEROLOGY: SPECIFIC IGG TO HAA}

Measurements of specific IgG to HAA by ELISA have not previously been reported. Therefore, results are given for all 203 sera. A strong negative correlation with current smoking was shown, as in the precipitin results (table). No dose response effect on the ELISA result was found when the numbers of cigarettes smoked were considered either as the number of cigarettes smoked a day (10 or less compared to greater than 10 cigarettes a day) or as pack-years smoked (20 or less compared to greater than 20 pack-years). No correlation with duration of exposure to the humidifiers, atopy, or positive skin prick test to HAA was found and no correlation between specific IgE and ELISA to HAA existed.

\section{SEROLOGY: SPECIFIC IGE TO HAA}

Figure 1 shows the distribution of specific IgE concentrations for the current, ex-, and never smokers. With either method of establishing a normal range for specific $\mathrm{IgE}$, only two values among the never smokers $(n=45)$ were above this range and both were less than $2 \%$ binding (mean $1 \cdot 35 \%$ ). For the ex-smokers $(n=29)$, four values were above $0.71 \%$ binding (mean $1.9 \%$ ) and three values were above $1 \cdot 0 \%$ (mean $2 \cdot 25$ ). For the current smokers (n $=52$ ) nine values were above $0.71 \%$ binding (mean $6.5 \%$ ) and eight values above $1 \cdot 0 \%$ (mean $7 \cdot 2$ ). The relative risk of developing raised specific IgE to HAA

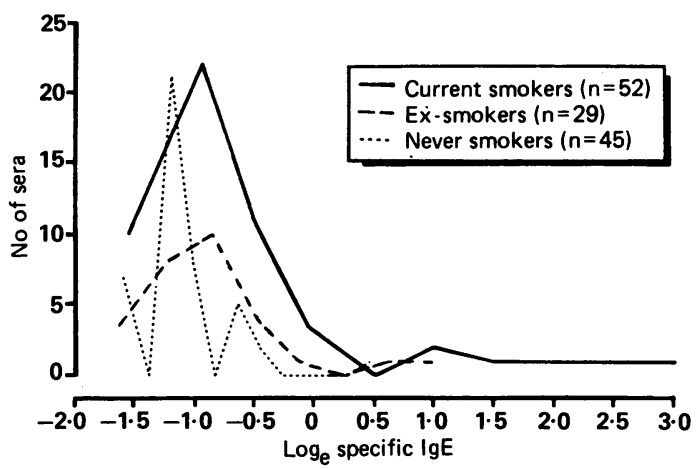

Figure $\log _{e}$ of specific IgE measurement to $H A A$ among current, ex-, and never smokers.

in current smokers was therefore 4-4.5 times that of non-smokers depending on which method was used to determine the normal range. No correlation existed between duration of exposure to the humidifiers and concentration of specific IgE.

We compared the specific IgE concentrations in ex-smokers who had been exposed to HAA while still smoking with the specific IgE concentrations in exsmokers who had not been exposed. Of the four exsmokers with a specific IgE value greater than $0 \cdot 71 \%$ binding, time since smoking was recorded in three. All three had been exposed to HAA as smokers. Of the remaining 46 ex-smokers, data were available for 45; of those 31 had been exposed as smokers and 14 had not. Similarly, all nine of the current smokers with a specific IgE value greater than $0.71 \%$ binding had been smoking at the start of their exposure to HAA. Of the remaining 65 current smokers for whom data were recorded, 57 were smokers at the start of exposure.

Of the 103 volunteers who were skin tested, 71 had sera available for detection of specific IgE. No excess of raised specific $\operatorname{IgE}$ above the defined normal concentrations was found among atopics $(n=20)$ compared with non-atopics.

\section{Discussion}

Smoking affects the immune response in many ways. A fall in the total $\gamma$-globulin concentration in smokers was noted in 1974. ${ }^{11}$ Current smokers have reduced concentrations of total IgG and $\operatorname{IgM}$ and increased concentrations of total IgE. ${ }^{12}$ Studies of subjects exposed to airborne antigens have shown reductions in specific IgG concentrations and in precipitating Geometric mean ELISA (95\% CI) according to smoking habit

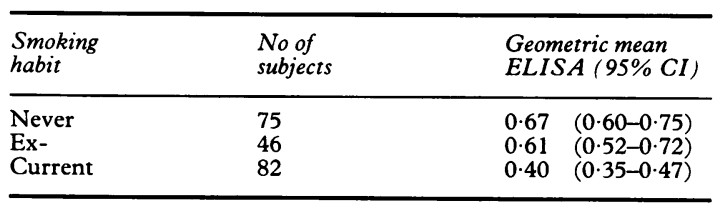


antibodies in smokers compared with nonsmokers. ${ }^{56}$ Other workers have shown that current smoking is not only associated with higher concentrations of specific IgE to inhaled occupational antigens, but that current smoking may confer a higher risk of developing work related asthma in response to these antigens. ${ }^{12}$

Our results show that specific IgG production to crude HAA is reduced in current smokers compared with never smokers, with ex-smokers occupying an intermediate position (table). No dose response according to the number of cigarettes smoked a day or the number of pack-years smoked was found.

We used two methods to define a normal distribution of specific IgE to HAA in the never smokers. With either method, smokers and ex-smokers had a higher relative risk of developing raised specific IgE concentrations against HAA than never smokers. Among those current smokers with a raised $\operatorname{IgE}$, we found no evidence of a dose response with the number of cigarettes smoked a day or the number of pack-years smoked.

The results of self recorded peak flow measurements were consistent with work related asthma in 12 workers. Of these, two had evidence of specific IgE antibody to humidifier antigens (both were current smokers). Of the 12 with work related asthma six were current smokers and nine had positive precipitins to humidifier antigens.

Our data are consistent with the hypothesis that smoking exerts an enhancing effect on production of IgE and an inhibitory effect on production of IgG in adults exposed to novel antigens in the workplace. The effect of smoking on production of IgE seems to affect only a small percentage of the smoking population (as most have normal values of specific $\operatorname{IgE}$ ), unlike its effect on production of IgG where smoking habit appears to be the dominant factor determining the concentration of IgG.

To test the theory that smoking exerts a permissive effect on production of $\mathrm{IgE}$ to novel antigen during the initial period of exposure, we compared the specific IgE concentrations in ex-smokers who had been exposed to HAA while still smoking with the specific IgE concentrations in ex-smokers who had not been exposed. Similarly, we compared the specific IgE concentrations in current smokers who were and current smokers who were not smoking at the start of their exposure. Although there were no statistically significant differences between the groups (ex- and current smokers) that had raised specific IgE concentrations and the groups that had not, the results are consistent with the theory that smoking at the onset of exposure may be one of the mechanisms involved in switching on production of IgE to a novel antigen.

The cause of the opposing effects of cigarette smoking on asthma and production of IgE and on allergic alveolitis or humidifier fever and production of IgG is not clear. ${ }^{13}$ The effect on asthma seems localised; smoking increased production of IgE antibody to ovalbumen in rats when inhaled but not when injected subcutaneously. ${ }^{14}$ Inhalation of cigarette smoke by guinea pigs caused mucosal inflammation and increased airway permeability to a marker protein, horseradish peroxidase. ${ }^{15}$ The permissive effect of cigarette smoking on production of IgE could be a consequence of increased permeability of the airway mucosa allowing antigen access to submucosal immunocompetent cells. The cause of the inhibitory effect of smoking on production of IgG and allergic alveolitis is even less clear but may be the consequence of reduced antigen penetration into the peripheral parts of the lungs of smokers or impaired presentation of antigen by alveolar macrophages; MHC2 expression and consequently the ability to present antigen is reduced in alveolar macrophages recovered from cigarette smokers by bronchoalveolar lavage. ${ }^{16}$

Requests for reprints to: Dr Finnegan, Chest Clinic, Barnet General Hospital, Barnet, Herts EN5 3DJ.

1 Venables KM, Topping MD, Howe W, Luczynska CM, Hawkins R, Newman-Taylor AJ. Interaction of smoking and atopy in producing specific IgE antibody against a hapten protein conjugate. $\mathrm{Br} \mathrm{Med} J$ 1985;290:201-4.

2 Zetterstrom O, Osterman K, Machado L, Johansson SGO. Another smoking hazard: raised serum IgE concentration and increased risk of occupational allergy. Br Med J 1981;283: 1215-7.

3 McSharry CM, Wilkinson PC. Cigarette smoking and the antibody response to inhaled antigens. Immunology Today (letter) 1986;7:98.

4 Venables KM, Stevens J, Nunn AJ, Stephens RJ, Farrer NM, Stewart M, Hughes EG, Newman-Taylor AJ. Increased risk of occupational allergy in smokers working in a platinum refinery. Thorax 1988;43:264P.

5 Finnegan MJ, Pickering CAC, Davies PS, Austwick PKC. Factors affecting the development of precipitating antibodies in workers exposed to contaminated humidifiers. Clin Allergy 1985;15:281-92.

6 Anderson K, Morrison SM, Bourke S, Boyd G. Effect of cigarette smoking on the specific antibody response in pigeon fanciers. Thorax 1988;43:798-800.

7 Burge PS, O'Brien IM, Harries MG. Peak flow records in the diagnosis of occupational asthma due to colophony. Thorax 1979;34:308-16.

8 Burge PS, O'Brien IM, Harries MG. Peak flow rate records in the diagnosis of occupational asthma due to isocyanates. Thorax 1979;34:317-23.

9 Finnegan MJ, Pickering CAC, Davies PS, Austwick PKC, Warhurst DC. Amoebae and humidifier fever. Clin Allergy 1987;17:235-42.

10 Burge PS, Finnegan MJ, Horsfield N, Pickering CAC. Occupational asthma in a factory with a contaminated humidifier. Thorax 1985;40:248-54.

11 Dales LG, Friedman GD, Sielgelaub AB, Selzer CC. Cigarette smoking and serum chemistry tests. J Chronic Dis 1974;27: 293-307.

12 Gerrard JW, Heiner DC, Ko CG, Mink J, Meyers A, Dosman A. Immunoglobulin levels in smokers and non smokers. Ann Allergy 1980;44:261-2.

13 Warren CPC. Extrinsic allergic alveolitis: a disease common in non-smokers. Thorax 1977;32:567-9.

14 Zetterstrom O, Nordvall SL, Bjorksten B, Ahlstedt S, Stelander $M$. Increased IgE antibody responses in rats exposed to tobacco smoke. J Allergy Clin Immunol 1985;75:594-8.

15 Hulbert WC, Walker DC, Jackson A, Hogg JC. Airway permeability to horseradish peroxidase in guinea pigs; the repair phase after injury by cigarette smoke. Am Rev Respir Dis 1981;123:320-6.

16 Lawrence EC, Fox TB, Hall BT, Martin RR. Deleterious effects of cigarette smoking on expression of Ia antigens by human pulmonary macrophages. Clin Res 1983;31:418a.

Accepted 2 July 1990 